\title{
AGAINST PHENOMENAL BONDING
}

\author{
S Siddharth ${ }^{1}$ \\ ${ }^{1}$ National Institute of Advanced Studies \\ (A recognized research centre of University of \\ Mysore), Benglauru, India
}

Discussion - Received: 20/02/2021 Accepted: 24/03/2021

\begin{abstract}
Panpsychism, the view that phenomenal consciousness is possessed by all fundamental physical entities, faces an important challenge in the form of the combination problem: how do experiences of microphysical entities combine or give rise to the experiences of macrophysical entities such as human beings? An especially troubling aspect of the combination problem is the subject-summing argument, according to which the combination of subjects is not possible. In response to this argument, Goff (2016) and Miller (2017) have proposed the phenomenal bonding relation, using which they seek to explain the composition of subjects. In this paper, I discuss the merits of the phenomenal bonding solution and argue that it fails to respond satisfactorily to the subject-summing argument.
\end{abstract}

Keywords: Panpsychism; combination problem; subject-summing; phenomenal bonding; constitutive panpsychism

\section{Introduction}

Panpsychism, the view that phenomenal consciousness or experientiality is possessed by all fundamental physical entities, faces an important challenge in the form of the combination problem: how do experiences of microphysical entities combine or give rise to the experiences of 
macrophysical entities such as human beings? (Chalmers 2016a) ${ }^{1}$ An especially troubling aspect of the combination problem is the subjectsumming argument, according to which the combination of subjects is not possible. In response to this argument, Goff (2016) and Miller (2017) have proposed the phenomenal bonding relation, with which they seek to explain the composition of subjects. In this paper, I argue that the phenomenal bonding solution does not work. I begin by introducing the combination problem and the subject-summing argument in $\S 1$, followed by an evaluation of Goff's proposal in $\S 2$. Goff, even while proposing his solution, admits that we do not have a positive conception of the phenomenal bonding relation; Miller, however, argues that we do have such a conception. In $\S 3$, I argue against Miller's attempt at forming a positive conception. The upshot of this discussion is that a panpsychist's best bet is in pursuing non-constitutive approaches in response to the combination problem.

\section{The Combination Problem}

The combination problem facing panpsychism is the question of explaining how the experiences of macrophysical entities, such as human beings, emerge from the experiences of microphysical entities. The challenge in providing an acceptable answer to this question is that the combination of experiences seems unintelligible - experiences just do not seem to be the kind of things that can combine. The most famous articulation of the combination problem is by William James, who says,

Take a hundred of them [feelings], shuffle them and pack them as close together as you can (whatever that may mean); still each remains the same feeling it always was, shut in its own skin, windowless, ignorant of what the other feelings are and mean. There would be a hundred-and-first feeling there, if, when a group or series of such feelings were set up, a consciousness belonging to the group as such should emerge. And this $101^{\text {st }}$ feeling would be a totally new fact; the 100 original feelings might, by a curious physical law, be a signal for its creation, when they came together; but they would have no substantial identity with it, nor it with them, and one could never deduce the one from the others, or (in any intelligible sense) say that they evolved it. (James 1890, 160, original emphasis)

\footnotetext{
${ }^{1}$ Also see Seager (1995), Goff $(2006,2009)$, and Coleman $(2012,2014)$ for more on the combination problem.
} 
Here, James argues that a combination of 'feelings' is unintelligible, for each feeling is 'windowless' - the content of one feeling cannot seep into another, or be shared with another. Given this, if there were a $101^{\text {st }}$ feeling emerging from a group of hundred feelings, such an emergence would be a 'totally new fact' - a case of brute emergence.

While James' argument talks of 'feelings' or experiences, it is the subjective component of experiences that has emerged as the most significant challenge-how do microphysical entities qua subjects (hereafter, microsubjects) combine to form other subjects such as macrophysical entities qua subjects (hereafter, macrosubjects)? (Chalmers 2016a) The combination of subjects, as Coleman (2012) notes, seems unintelligible and thus impossible, due to certain intuitions about the nature of subjects. ${ }^{2}$ First, subjects seem to be ontological unities, or entities that, in the words of Galen Strawson (2009), are "fundamentally unified, utterly indivisible as the particular concrete phenomenon it is, simply in being, indeed, a total experiential field" (377-78). Such a unified subject experiencing a complex experience cannot be broken down into and understood in terms of multiple subjects, each experiencing one aspect or 'part' of the complex experience. In other words, a subject understood as an ontological unity cannot be broken down into 'parts'. ${ }^{3}$ How can a macrosubject, then, be composed of microsubjects?

Closely related to the unity of a subject is its privacy ${ }^{4}$ - a subject's experience is private to that subject, and it seems unintelligible how another subject could access the same token experiential content as the first subject. One could, perhaps, imagine a situation where two subjects experience identical experiential content. For example, consider a future where we have developed advanced scientific equipment that allows us to invoke specific experiences in a subject. Using this equipment, a scientist can bring about identical experience as of eating an apple in two friends. Such a situation would be a case where there are two tokens of the same experiential content (the experience as of eating an apple), each experienced by a distinct subject, and not a case where two distinct subjects

\footnotetext{
${ }^{2}$ Coleman (2012) himself does not use the terms that I use here-ontological unity and privacy - but makes the same point. For example, he is alluding to both unity and privacy when he says, "...our notion of a subject, is precisely the notion of a discrete, essentially inviolable sphere of conscious-experiential goings-on. My mind is separate from your mind, is separate from her mind, and so on. None of us has, nor can have, access to the consciousness of another, to what it is like for them" (Coleman 2012, 145, emphasis in original).

${ }^{3}$ See Barnett (2008) for more on the intuition that subjects are mereological simples i.e. without proper parts.

${ }^{4}$ The term privacy is borrowed from Roelofs (2019).
} 
experience the same token experiential content. This is what is meant by the privacy of subjects - two subjects cannot experience the same token experiential content. If the experiential content of one subject cannot be experienced by another, how can the experiential content of microsubjects constitute the experience of a macrosubject? Thus, we see that the ontological unity and privacy of subjects seem to render the combination of subjects impossible.

This problem facing panpsychism has come to be known as the nosumming-of-subjects argument (Goff 2016) or simply the subject-summing argument (Chalmers 2016a). Goff articulates the argument as follows:

1. Conceptual Isolation of Subjects-For any group of subjects, instantiating certain conscious states, it is conceivable that just those subjects with those conscious states exist in the absence of any further subject.

2. Transparency Conceivability Principle-For any proposition $\mathrm{P}$, if (A) P involves only quantifiers, connectives, and predicates expressing transparent concepts, and (B) $\mathrm{P}$ is conceivably true upon ideal reflection, then $\mathrm{P}$ is meta-physically possibly true.

3. Phenomenal transparency-Phenomenal concepts are transparent.

4. Metaphysical Isolation of Subjects - For any group of subjects, instantiating certain conscious states, it is possible that just those subjects with those states exist in the absence of any further subject (from 1, 2, and 3).

5. For any group of subjects, those subjects with those conscious states cannot account for the existence of a further subject (from 4).

6. Therefore, panpsychism is false (from 5) (Goff 2016, 291-92)

Premise 1 states that one can conceive of $n$ subjects and their experiences without the existence of a further, $n+l^{\text {th }}$ subject. This, as noted above, is underpinned by the intuition that subjects are ontological unities. Premise 2 states that if any proposition that involves transparent concepts is conceivably true, it is also possibly true. Further, our concepts of experiential phenomena, including of subjects are transparent concepts, according to premise 3. Thus, from 1, 2 and 3, it follows that it is possible that $\mathrm{n}$ subjects exist without the sum of these $\mathrm{n}$ subjects - $\mathrm{a}$ further, $\mathrm{n}+1^{\text {th }}$ subject-existing. If this were the case, it follows that panpsychism is false, for the existence of microsubjects cannot explain the emergence of macrosubjects (such as human subjects), leading to an explanatory gap. Faced with this explanatory gap, panpsychism loses its attraction as an alternative to physicalism and dualism. 
A panpsychist could argue that the relation between microsubjects and macrosubjects is not one of composition but something else, such as ontological emergence. Chalmers (2016b) refers to panpsychist positions that propose that macroexperiences are composed of microexperiences as constitutive panpsychism, and those that do not as non-constitutive panpsychism. For the purpose of this paper, I ignore non-constitutive views, and deal only with the combination problem facing constitutive versions. I hence reserve the term 'panpsychism' for its constitutive version, unless otherwise specified.

\section{The Phenomenal Bonding Response}

In response to the subject-summing argument, Goff (2016) proposes the phenomenal bonding relation. He concedes that the mere existence of $\mathrm{n}$ subjects and their experiential content in themselves does not necessitate the presence of an $n+1^{\text {th }}$ subject. However, Goff argues that it is possible for the n subjects to enter into a relation-"be involved in some state of affairs" (Goff 2016, 292) —which necessitates the existence of a composite macrosubject. He calls this relation the phenomenal bonding (PB) relation. A collection of bricks in themselves do not compose a wall but do so only when they are related in a particular manner-spatially arranged in certain ways. Goff argues that similarly, a collection of subjects in themselves do not compose a further subject, but do so only when they are related by the $\mathrm{PB}$ relation. If we were to accept the phenomenal bonding relation, a panpsychist can respond to the subject-summing argument by arguing that premise 4 does not lead us to conclusions 5 and 6 , for subjects which share the phenomenal bonding relation can account for a further subject of experience.

Goff himself admits that we have no positive conception of the PB relation. However, he contends that it is understandable why we have no conception of a relation between subjects, for we have neither perceptual nor introspective access to subjects barring our own. Despite having no positive conception of the PB relation, Goff thinks that there is no reason to deny that such a relation between subjects is possible; just as panpsychists have to identify some phenomenal property with the physical property 'charge' in a brute manner, the $\mathrm{PB}$ relation too will have to be identified with some physical relation (Goff 2016).

It is here that Goff's proposal faces a problem. The thrust of the subject summing argument is not that the subject-combination relation cannot be identified with some physical relation in a brute manner-we could, if we had good reasons to believe that subject combination is possible. Rather, 
as Coleman (2012) notes, it is that the notion of a composite subject itself seems incoherent, and thus impossible, on account of the ontological unity and privacy of subjects. ${ }^{5,6}$ Given this, the subject summing argument ought to be understood as the problem of the unintelligibility, incoherence and thus, impossibility of relations such as the PB relation. By simply defining and stipulating the PB relation in terms of the role we want it to play, without either an argument for how subject combination is possible in the first place or a positive conception of the relation, Goff is assuming what ought to be argued for, and thus begging the question.

One can adopt such a method of defining relations in a brute manner to defend almost any unintelligible relation. For example, consider the example of 'volume' in Euclidean space. When there are two perfect cubes of 1-unit volume each conjoined together at one of their surfaces with no overlap of volume, the total volume of the newly formed cuboid would be 2 units. If one were to follow Goff's method, one can simply define a new relation called 'volume-contraction' such that when the two cubes are conjoined, the total volume would not be 2 units, but only 1.5 units. Further, it could be argued that while such a relation is unintelligible to us, this is so only because volume contraction is a brute fact about the world. One can immediately see that positing such a volume-contraction relation is wrong. Without a further positive characterisation of the volumecontraction relation, it is unintelligible to us how the total volume of two cubes with conjoined surface can be 1.5 units instead of 2 units. By proposing the volume-contraction relation as a brute posit, we would be assuming what ought to be explained (that such volume contraction is possible). Similarly, by simply defining the phenomenal bonding relation such that it fulfils the role of subject composition, Goff is assuming what ought to be explained in the first place.

\section{Positive Conception of Phenomenal Bonding}

Proponents of the PB relation can avoid begging the question if they are able to provide a positive conception of the relation. This is what Miller

\footnotetext{
${ }^{5}$ This distinction between two versions of the subject combination problem is made more clearly by Shani and Williams (2021). In the first version, similar to Goff's (2016) articulation, it is argued that no arrangement of subjects necessitates a composite subject, and hence, subject composition is impossible. According to the second, similar to Coleman's (2012) articulation, it is argued that the notion of a composite subject itself is unintelligible and incoherent, and hence, subject composition is impossible. Shani and Williams argue that the second is the stronger and more difficult challenge facing panpsychists.

${ }^{6}$ I would like to thank an anonymous reviewer for pressing this point.
} 
(2017) attempts. He identifies three conditions a relation ought to fulfil to qualify as the phenomenal bonding relation:

- It must be a phenomenal relation i.e., there should be a what-it-islike feel associated with it.

- Its relata should be subjects qua subjects.

- It must necessitate further subjects distinct from the subjects it holds between (Miller 2017).

Miller further identifies co-consciousness as the relation that fulfils these conditions and fits the role required of the PB relation. By coconsciousness, Miller refers to the "the relation in virtue of which conscious experiences have a conjoint phenomenology or a conjoint whatit-is-like-ness" (Miller 2017, 548). For example, when one looks at a bird while listening to it chirp, the auditory quality of the bird's chirp and the visual quality of its appearance are experienced together as a unified experience. The relation that unifies these two qualities to produce the conjoint phenomenology of our experience is what Miller refers to as coconsciousness.

Miller contends that the co-consciousness relation is known to us through our own experiences, for it feels some way for us to experience the qualities in a unified manner. That is, there is a phenomenal quality associated with the co-consciousness relation. It thus fulfils the first condition to fit the role of the PB relation. The second condition facing coconsciousness is that it ought to hold between subjects qua subjects. In the example given earlier, the co-consciousness relation holds between two qualities that are experienced by the same subject. Can we conceive of a similar co-consciousness relation that holds between two subjects instead of qualities? While Goff argued that we cannot conceive of any relations between subjects qua subjects because we have epistemic access through introspection only to one subject - our own-Miller contends that this limitation can be overcome. He proposes that one could form a positive conception of inter-subject co-consciousness through analogical extension.

Analogical extension, according to Miller, is a method of concept formation wherein we start with a case where we have a clear conception (hereafter, the prototype scenario), and use this conception to form a concept in another scenario that is not wholly similar to the first (hereafter, the target scenario). Some examples of analogical extension he gives are: 
- We form a concept of the molecule as a physical object using visual representations of macrophysical entities that we have, though we do not have visual representations of molecules.

- We form a concept of the relation 'earlier than' as it applies to vast tracts of time (e.g., on cosmic scale) though we only experience events across much smaller periods (like a few second, days, months etc.).

- We form a concept of similarity of phenomenal states across subjects, though we only experience our own phenomenal states and conceive of them as being similar to each other.

In all these examples, we use the concept from a known scenario to form a concept in a different scenario. Miller contends that we can use this method to form a positive conception of the inter-subject co-consciousness relation based on our concept of intra-subject co-consciousness.

However, this approach does not work for the following reasons. First, consider the examples cited by Miller. It is important to note that in each of these examples, the relata in the prototype and target scenarios are of the same type. In the case of the 'earlier than' relation, the relata are eventsin-time in both scenarios. In the case of phenomenal similarity, the relata are qualities-experienced-by-a-subject. In the case of molecules as physical objects, the relata are objects-in-space in both scenarios. In contrast to these three examples, in the case of co-consciousness, the relata in the prototype and target scenarios are not of the same type. The relata of the intra-subject co-consciousness relation - the prototype-are qualities experienced by a subject. On the other hand, in the case of the inter-subject co-consciousness relation - the target - the relata are subjects qua subjects and not qualities experienced by a subject (same or different subjects). This is as per Miller's own criteria that any relation has to meet to qualify as the phenomenal bonding relation (the second criterion listed above). Thus, unlike the examples used by Miller to outline analogical extension, the type of relata in the prototype and target scenarios are different in the case of the co-consciousness relation. For this reason, analogical extension cannot help us form a positive conception of co-consciousness between subjects qua subjects.

Even if we were to ignore this drawback, there is another problem in using analogical extension to form a positive conception of inter-subject coconsciousness. It seems that if one were allowed to use analogical extension to form a conception of inter-subject co-consciousness, one could use analogical extension to form positive conceptions of relations which we know are definitely not acceptable. Consider the example from earlier, of volume contraction of two cubes in Euclidean three-dimensional 
space, occupying 1-unit volume each, conjoined together with one overlapping surface and no overlapping portion of volume. Everyone would accept that such a volume-contraction relation is inconceivable. However, it seems that one can use analogical extension (of the sort required for inter-subject co-consciousness) to form a positive conception of the volume-contraction relation too. One could argue thus:

Start with the following prototype scenario: volume contraction relation in cases where two cubes, each individually occupying 1-unit volume, overlap not just along a surface but in part of their volumes as well. In this case, the volume contraction relation - the relation between the cubes on account of which the total volume occupied by them together is less than 2 units - is intelligible and we have a positive conception of such a relation. Now, we can use the positive conception of volume contraction in volume-overlapping cases as the prototype scenario and form a positive conception of volume contraction in the scenario where there is overlap only along a surface (and no overlap of volume).

Would such a proposal be acceptable? Can we claim to have a positive conception of the volume-contraction relation based on this argument? Clearly, we cannot. The lesson here is that analogical extension works only in some cases. How do we know that co-consciousness relation is not like volume-contraction (where analogical extension does not work) but like phenomenal similarity (where analogical extension does work)? In the cases of inter-subject co-consciousness and volume-contraction, it is not just that we do not have a positive conception of these relations, but that we also have a priori reasons to believe that the relation in question leads to contradictions. For example, given our conception of Euclidean space, cubes and volumes, it is a priori true that the volume of non-overlapping cubes conjoined along a surface is just the sum of the volumes of the two cubes. Positing volume contraction without changing any of our initial conceptions (of what Euclidean space, cubes or volumes are) leads to a contradiction. Similarly, given ontological unity and privacy of subjects, positing co-consciousness relation between two subjects leads to contradictions - if inter-subject co-consciousness and composite subjects were possible, privacy and ontological unity of subjects would be false. In contrast, we have no a priori reason to believe that phenomenal similarity between qualities experienced by different subjects leads to any contradiction. Hence, we can use analogical extension to form a positive conception of this relation based on phenomenal similarity between qualities experienced by the same subject. Similarly, we have no a priori reason to believe that the 'earlier than' relation, when applied to vast tracts 
of time, leads to contradictions. Hence, we can use analogical extension to form a positive conception of this relation based on the known prototype.

To summarise, Miller's proposal to form a positive conception of the intersubject co-consciousness relation through analogical extension does not work for two reasons. First, co-consciousness as known to us is a relation that holds between qualities and not between subjects qua subjects. On the other hand, the relation we want to form a positive conception of (intersubject co-consciousness) is required to hold between subjects qua subjects. Second, the kind of analogical extension that is required from a positive conception of inter-subject co-consciousness can be used to form a positive conception of relations that we know are definitely not possible (such as the volume-contraction relation). This serves as a reductio ad absurdum against Miller's argument.

Miller's proposal is now in the same boat as Goff's - both fail to provide a positive conception of the phenomenal bonding relation. Without a positive conception, the phenomenal bonding solution simply assumes that composite subjects are possible, while the possibility of composite subjects is what the subject-summing argument questions in the first place.

\section{Conclusion}

The phenomenal bonding solution to the combination problem does not work, for we have no positive conception of such a relation, while we have good reasons to believe that such a relation is not possible. Goff's argument for the phenomenal bonding relation in the absence of a positive conception is not acceptable; neither is Miller's attempt at motivating a positive conception of the relation. In the absence of such a conception, proponents of this approach are guilty of begging the question against the subject-summing argument.

Where does this leave panpsychism? While it is only one approach to constitutive panpsychism that has been refuted here, it is likely that the challenge posed here would equally apply to any solution that seeks to explain combination of subjects - in the absence of a positive conception of the subject-composition relation, the solution would be guilty of assuming what ought to be argued for. Thus, in response to the combination problem, a panpsychist would be better off pursuing a nonconstitutive ontology. 


\section{Acknowledgments}

This research was carried out as part of my doctoral work, and forms a part of the thesis I submitted to the University of Mysore for award of the Ph.D. degree. I would like to thank Dr. Indrani Bhattacharjee and an anonymous referee for helpful comments on earlier drafts of this paper.

\section{REFERENCES}

Barnett, David. 2008. 'The Simplicity Intuition and Its Hidden Influence on Philosophy of Mind'. Nous 42 (2): 308-35. https://doi.org/10.1111/j.1468-0068.2008.00682.x

Chalmers, David J. 2016a. 'The Combination Problem for Panpsychism'. In Panpsychism: Contemporary Perspectives, edited by G. Brüntrup and L. Jaskolla. Oxford: Oxford University Press. 2016b. 'Panpsychism and Panprotopsychism'. In Panpsychism: Contemporary Perspectives, edited by G. Brüntrup and L. Jaskolla, 19-47. Oxford: Oxford University Press.

Coleman, Sam. 2012. 'Mental Chemistry: Combination for Panpsychists'. Dialectica 66 (1): 137-66.

https://doi.org/10.1111/j.1746-8361.2012.01293.x.

- 2014. 'The Real Combination Problem: Panpsychism, MicroSubjects, and Emergence'. Erkenntnis 79: 19-44. https://doi.org/10.1007/s10670-013-9431-x.

Goff, Philip. 2006. 'Experiences Don't Sum'. Journal of Consciousness Studies 13 (10-11): 53-61.

2009. 'Why Panpsychism Doesn't Help Us Explain Consciousness'. Dialectica 63 (3): 289-311.

https://doi.org/10.1111/j.1746-8361.2009.01196.x

2016. 'The Phenomenal Bonding Solution to the Combination Problem'. In Panpsychism: Contemporary Perspectives, edited by G. Brüntrup and L. Jaskolla, 283-302. Oxford: Oxford University Press.

James, William. 1890. The Principles of Psychology. New York: Henry Holt \& Company.

Miller, Gregory. 2017. 'Forming a Positive Concept of the Phenomenal Bonding Relation for Constitutive Panpsychism'. Dialectica 71 (4): 541-62.

https://doi.org/10.1111/1746-8361.12207

Roelofs, Luke. 2019. Combining Minds: How to Think About Composite Subjectivity. New York: Oxford University Press.

Seager, William. 1995. 'Consciousness, Information and Panpsychism'. Journal of Consciousness Studies 2 (3): 272-88. 
Shani, Itay, and Heath Williams. 2021. 'The Incoherence Challenge for Subject Combination: An Analytic Assessment'. Unpublished manuscript, last modified February 18, 2021.

Strawson, Galen. 2009. Selves: An Essay in Revisionary Metaphysics. Oxford University Press. 